\title{
Arthropod infestation sites and induced defence can be traced by emission from single spruce needles
}

\author{
Marie Danielsson ${ }^{1} \cdot$ Tao Zhao $^{1,2} \cdot$ Anna-Karin Borg-Karlson ${ }^{1}$ D
}

Received: 13 November 2018 / Accepted: 24 January 2019 / Published online: 13 February 2019

(c) The Author(s) 2019

\begin{abstract}
Emissions of defence chemicals from Norway spruce seedlings can be induced by feeding arthropods or by exogenous hormonal application. Some defence chemicals may attract or repel associated arthropods. The aim of this study was to show that it is possible to detect and collect stress-induced volatiles from micro sites, such as at the scale of a single needle, in vivo by using SPME. Methyl jasmonate application on the stem of Norway spruce seedlings induced emission of $(E)-\beta$-farnesene only from the needles closest to the application site. Emissions of $(E)$ - $\beta$-farnesene, $(E, E)-\alpha$-farnesene and $(E)$ - $\alpha$-bisabolene were only detected from needles infested by the spider mite Oligonychus ununguis. The total volatile amount detected by SPME-GC-MS reached a considerable mass of $14 \mathrm{ng} / \mathrm{needle} / 24 \mathrm{~h}$, suggesting that emission from damaged and stressed conifers might have a larger impact on the macro climate than previously estimated.
\end{abstract}

Keywords $(E)-\beta$-Farnesene $\cdot$ Methyl jasmonate $\cdot$ Picea abies $\cdot$ Solid-phase microextraction (SPME) $\cdot$ Stress-induced volatiles $\cdot$ Oligonychus ununguis

\section{Introduction}

Plants emit a multitude of compounds, which influence their biotic environment. These volatiles may attract herbivores for feeding and egg deposition, as well as their predators and parasitoids (Hilker and Fatouros 2015; Aartsma et al. 2017). They may also mediate plant-plant signalling (Dudareva et al. 2006) and contribute to the content of volatile organic compounds in the atmosphere (Goldstein and Galbally 2007). Conifers of the family Pinaceae produce terpenoids extensively, some of these terpenoids are stored in resin ducts in the plant tissues and others are directly

Handling Editor: Dagmar Voigt.

Electronic supplementary material The online version of this article (https://doi.org/10.1007/s11829-019-09677-0) contains supplementary material, which is available to authorized users.

Anna-Karin Borg-Karlson

akbk@kth.se

1 Department of Chemistry, School of Engineering Sciences in Chemistry Biotechnology and Health, KTH, 10044 Stockholm, Sweden

2 Department of Science and Technology, Örebro University, 70281 Örebro, Sweden released into the environment (Copolovici and Niinemets 2016). In addition to the constitutive compounds, many conifer species have an induced production of terpenes and other stress-related compounds when wounded and infested by insects or other arthropods (Franceschi et al. 2002, 2005; Kännaste et al. 2009; Kurz et al. 2008; Zhao et al. 2011; Krokene 2015).

Detection, collection and analysis of plant volatiles are essential steps in understanding plant-environment interactions. A common technique that has been used for thermally sensitive compounds is adsorption to a variety of chemical structures with subsequent desorption using solvents (Fäldt et al. 2000; D'Alessandro and Turlings 2006). However, evaporating the solvents results in concentration of the solvent impurities, which is problematic for chemical analyses. Solvent-free methods, such as the solid-phase microextraction (SPME) adsorb the volatiles on a polymer (fibre coating) with selected polarity followed by subsequent desorption by heating, are advantageous for studies of volatile emissions. SPME was introduced by Zhang and Pawliszyn (1993) and since then has been widely used in chemical ecology (Borg-Karlson and Mozuraitis 1996; Lundborg et al. 2016a, b and references therein). It is predominantly a qualitative sampling method, and different fibre coatings make it possible to tailor the extraction for the selective compounds 
(Mani 1999; Fäldt et al. 2000). It is non-invasive and simple to handle which makes it suitable for monitoring volatiles emitted by living organisms (Borg-Karlson and Mozuraitis 1996; Augusto and Valente 2002; Chung et al. 2016; Araniti et al. 2018). SPME is one of few options for sampling trace amounts of compounds, it can be adjusted to thermosensitive compounds by lowering the heating temperature in the injector and we can take advantage of our experience using SPME, that certain fibre coatings favour topical compounds with a higher molecular weight.

Methyl jasmonate (MeJA), a volatile derivative of the plant hormone jasmonic acid, plays a role in the stressinduced biosynthetic pathway. MeJA is often used to induce plant stress in studies under controlled conditions (Phillips et al. 2006) and also in practical applications for protecting newly planted conifer seedlings (Björklund et al. 2005). Although the complete volatile profile differs, the main volatiles released by Norway spruce seedlings infested with the spider mite Oligonychus ununguis (Kännaste et al. 2009) are the same as the major ones emitted by MeJA-treated plants (Martin et al. 2003), e.g. (E)- $\beta$-farnesene, linalool and methyl salicylate. In this study, we compared volatiles released by plants naturally infested with spider mite and manually treated with MeJA to test if it is possible to detect and collect rapidly formed stress-induced volatiles from micro sites, e.g. at the scale of a single spruce needle. Since the volatile emission from stressed sites may influence plant selection by herbivores as well as their predators and parasites, we applied non-invasive, well in situ manageable SPME. Results obtained show that both mite infestation and MeJA application induce highly local stress reactions in young Norway spruce (Picea abies [L.] H. Karst, Pinaceae) plants which can be easily detected and followed in vivo at the single needle scale using SPME.

\section{Materials and methods}

\section{Plant material}

Two-year-old Norway spruce seedlings from open crosses (obtained from Anders Lindström, Dalarnas Högskola, Sweden) were used for methyl jasmonate (MeJA) treatment. Plants were grown in a greenhouse and transported to the laboratory at KTH (Royal Institute of Technology, Sweden) where they were kept at $22{ }^{\circ} \mathrm{C}$, ca $50 \%$ relative humidity (RH) and a 20/4 (light/dark) photoperiod for two weeks before the experiments started (Fig. 1).

In a separate room, three-year-old plants of clone line 1509 from the botanical archives of Skogforsk (the Forestry Research Institute of Sweden) were used for spruce spider mite infestation (Oligonychus ununguis Jacobi, Acari, Tetranychidae). These plants were grown in a greenhouse and

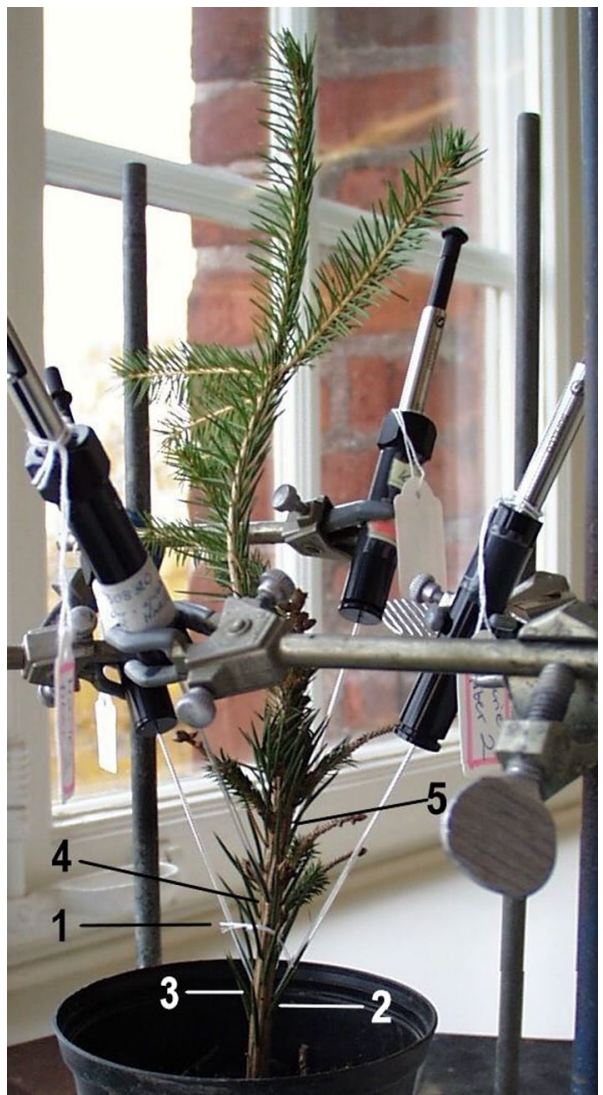

Fig. 1 Single needle collection setup. (1) MeJA solution was applied at the lowest $5 \mathrm{~cm}$ of the stem. $(2,3)$ Needles growing on the MeJAtreated area, covered with thin glass tubes with SPME's holders mounted and fibres exposed inside. (4) needle growing $1 \mathrm{~cm}$ above the treated area. (5) Needle growing $2 \mathrm{~cm}$ above the treated area. SPME holder and glass tube mounted against the stem $10 \mathrm{~cm}$ above treated area

transported to $\mathrm{KTH}$ where they were kept at a temperature of $22{ }^{\circ} \mathrm{C}$, ca $50 \% \mathrm{RH}$ and $18 / 6$ (L/D) photoperiod for two weeks before the experiments started.

All plants were planted in commercial plant soil (Hammenhög) in $12-\mathrm{cm}$ plastic pots three months before the experiments (Fig. 1).

\section{Chemicals}

Methyl jasmonate (98\%, Sigma-Aldrich, Inc.) was dissolved in deionized water to $45 \mathrm{mM}$ concentration with the help of four drops of the surfactant Nordex Debitol Extra (Nordex Sverige AB, Uppsala, Sweden). Compounds for calibration and the SPME competition study were obtained from commercial sources. (-)- $\alpha$-Pinene ( $\geq 99 \%),(S)-(-)$-limonene $(\geq 99.5 \%)$, myrcene $(90 \%)$ and bornyl acetate $(90 \%)$ were purchased from Fluka TM (Honeywell International, Inc.), linalool from Koch-Light Laboratories (Pty) Ltd. (rac., $\geq$ 
90\%), methyl salicylate ( $\geq 99 \%$ ) from Lancaster Synthesis and $(E)$ - $\beta$-farnesene $(\geq 95 \%)$ from Bedoukian Research Inc.

\section{MeJA treatment of plants and collection of volatiles from single needles}

Four Norway spruce seedlings of similar size were used in the MeJA experiment. For each plant, four needles with different positions on the stem were chosen: two on the lowest $5 \mathrm{~cm}$ of the stem, measured from the base of the soil surface, one $6 \mathrm{~cm}$ and one $7 \mathrm{~cm}$ from the soil surface (i.e. two needles growing on the area later treated with MeJA and two needles 1 and $2 \mathrm{~cm}$ above the MeJA-treated area). Small conical glass tubes (diameter 1-2 mm, $8 \mathrm{~cm}$ length, volume $\sim 0.6 \mathrm{~mL}$ ) were made by cutting off the tip of Pasteur pipettes (VWR International GmbH, Darmstadt, Germany). Glass tubes were placed over each needle without touching the needles and the fibre of the SPME device was inserted into the opposite end of the glass tube (Fig. 1). In addition, one glass tube was placed towards the stem about $10 \mathrm{~cm}$ above the MeJA-treated area to serve as a control and for background collection. After the glass tubes were mounted, an SPME fibre was carefully introduced to each tube and exposed for $22 \mathrm{~h}$, collecting headspace samples of single needles (day 0 , as control).

On day 1, a $45 \mathrm{mM}$ (1:100) solution of MeJA in distilled water was applied, with a soft painting brush $(1 \mathrm{~mm}$, synthetic hair), to the first $5 \mathrm{~cm}$ of the stem, measured from the base of the soil surface (approximately $0.4 \mathrm{~mL}$, corresponding to $4 \mathrm{mg} \mathrm{MeJA}$, was applied to each seedling). The glass tubes were in place over the chosen needles during application. After MeJA application, another 22-h collection period started. This gave a total of eight collections from needles on untreated areas both before and after treatment.

\section{Spider mite infestation and collection of volatiles from single needles in spider mite-infested plants}

Several needles of prepared spruce clonal trees were naturally infested with a low abundance of spider mites (all instars pooled together), while other needles on the same plants were undamaged, and not infested with spider mites. Infested and uninfested parts of four plants were identified using a magnifying glass. For each SPME collection, two needles were randomly chosen on the same plant, one from the uninfested area and one in an area infested with one or two adult mites per needle. The infested and uninfested areas were located on different branches of the plant, typically growing on opposite sides at a similar height on the plant stem.

Glass tubes were placed over needles and volatiles collected by SPME as described. The glass tubes were a little wider (diameter 2-3 $\mathrm{mm}$ ) to avoid crushing the mites on the spruce needles. The emissions of single needles were analysed on each plant, involving two or three pairs of healthy/ infested needles, leading to a total of ten collections from mite-infested needles and ten collections from uninfested needles. Each infested needle was compared with an uninfested needle on the same plant and at the same sampling time. Thus, abiotic factors and background volatiles should be similar for both infested and control needles.

\section{Volatile analysis}

Solid-phase microextraction (SPME) with $65 \mu \mathrm{m}$ polydimethylsiloxane/divinylbenzene (PDMS/DVB) coating (Supelco, Sigma-Aldrich Inc.) was used to collect the volatiles. Before each sampling period, the fibres were cleaned by heating at $220{ }^{\circ} \mathrm{C}$ for $5 \mathrm{~min}$ in a helium flow.

The volatile samples collected with SPME were analysed with a Varian 3400 gas chromatograph (GC, SpectraLab Scientific Inc. Markham, Canada) connected to a Finnigan SSQ 7000 mass spectrometer (Finnigan Corp., San Jose, USA, EI, $70 \mathrm{eV}$, ion source temperature: $150^{\circ} \mathrm{C}$, scan range $33-400 \mathrm{~m}^{*} \mathrm{z}^{-1}$ ) with a transfer line kept at $240{ }^{\circ} \mathrm{C}$. The fibres were inserted for $2 \mathrm{~min}$ at $220^{\circ} \mathrm{C}$ (split/splitless $30 \mathrm{~s}$ ) to an $\mathrm{SPB}^{\mathrm{TM}}-1$ column (Supelco ${ }^{\circledR}$ Analytical, Munich, Germany, $30 \mathrm{~m}, 0.25 \mathrm{~mm}$ id and $0.25 \mu \mathrm{m}$ film thickness). The column temperature was $40^{\circ} \mathrm{C}$ for one minute, thereafter increasing by $15^{\circ} \mathrm{C}^{*} \min ^{-1}$ to $230{ }^{\circ} \mathrm{C}$ and then held at this temperature for $1 \mathrm{~min}$. Linalool, $(E)-\beta$-farnesene, $(E, E)-\alpha$-farnesene and (E)- $\alpha$-bisabolene were clearly separated and identified by comparing the mass spectra and retention times with available reference compounds and literature data. Although, SPME is a qualitative approach, the amounts of these volatiles released from Norway spruce needles were estimated by weighted calibration curves (Miller and Miller 2005) based on direct injection of dilutions of $(E)$ - $\beta$-farnesene and linalool (see Supplementary material).

\section{Selectivity of SPME: SPME competition}

The possible competition of other volatiles adsorbed on the fibre during collection of $(E)$ - $\beta$-farnesene was investigated. The adsorption of $(E)$ - $\beta$-farnesene by the fibre was compared with adsorption of $(E)$ - $\beta$-farnesene in a mixture with six other common spruce compounds ( $\alpha$-pinene, limonene, myrcene, bornyl acetate, linalool and methyl salicylate) of the same concentration $\left(1: 100000,8 \mathrm{ng}^{*} \mu \mathrm{L}^{-1}\right)$. The compounds were chosen because they are present in spruce needles and could possibly be released during the adsorption experiment (see below). A similar setup to that for single needle experiments was used. First, a $1 \times 1.5 \mathrm{~mm}$ piece of filter paper (Munktell, Ahlstrom-Munksjö, Helsinki, Finland) was placed inside the glass tube. One $\mu \mathrm{L}$ of one of the terpene solutions was applied on the filter paper, thereafter 
the tube was sealed with aluminium foil and volatile sampling was performed as before with five repetitions of each experiment.

In addition to volatiles, spruce needles also release water to the environment. To ensure that water molecules did not cover the fibre, and outcompete the nonpolar volatiles from being adsorbed to the fibre coating, a similar experiment using the mixture described above was made. For these experiments $(n=7)$, one $\mu \mathrm{L}$ of deionized water was added to the filter paper before sealing with aluminum foil.

\section{Statistical analysis}

The emission of stress-related volatiles (e.g. linalool, $(E)$ $\beta$-farnesene, $(E, E)$ - $\alpha$-farnesene and $(E)$ - $\alpha$-bisabolene) from needles situated in MeJA-treated and untreated parts of the Norway spruce plants were compared using a $t$-test. The emissions from needles infested by the spider mite and uninfested needles were compared using a paired $t$-test. All t-tests were performed with the data analysis tool in Excel 2010 (Microsoft Corp., Redmond, WA, USA). Two-tail p-values are presented.

\section{Results}

\section{Needle-released volatiles of MeJA-treated plants}

Needles on MeJA-treated areas emitted significantly more (E)- $\beta$-farnesene (0.1-4 ng detected) than needles growing $1-2 \mathrm{~cm}$ above the treated seedling stem areas $(t$-test, $p=0.01)$, of which only one needle $(n=8)$ emitted small amounts of $(E)$ - $\beta$-farnesene (Fig. 2). In addition, $(E, E)-\alpha-$ farnesene, $(E)-\alpha$-bisabolene and linalool were detected in the headspace of the needles on the MeJA-treated stem. Before application of MeJA, none of the stress-induced compounds were present in the headspace of the needles and none of them were found in the background collections, neither before nor after application of MeJA.

\section{Needle-released volatiles from mite-infested needles}

Needles infested with the spruce spider mite emitted significantly larger amounts of $(E, E)$ - $\alpha$-farnesene $(p=0.02)$ and $(E)$ - $\alpha$-bisabolene $(p=0.03)$ than uninfested needles of the same plant as well as increased emission of $(E)$ - $\beta$-farnesene $(p=0.06)$ (Fig. 3). The total amounts of volatiles collected from single needles were estimated by calibration of the GC-MS with direct injection of $(E)-\beta$-farnesene standards and ranged between 0.5 and $14 \mathrm{ng}$.

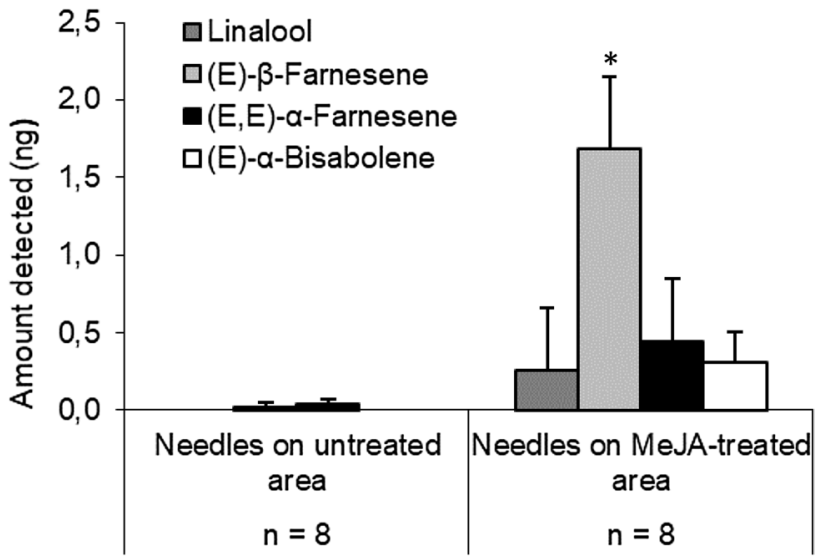

Fig. 2 The amount of linalool, (E)- $\beta$-farnesene, $(E, E)$ - $\alpha$-farnesene and $(E)$ - $\alpha$-bisabolene $($ mean $\pm \mathrm{SE}$ ) released from needles on MeJAtreated and untreated area, $24 \mathrm{~h}$ after brushing $44.5 \mathrm{mM}$ MeJA on the lowers oart of the stem. The star denotes the significant difference at $p=0.01$ level between emission from needles on untreated area and needles on MeJA-treated area

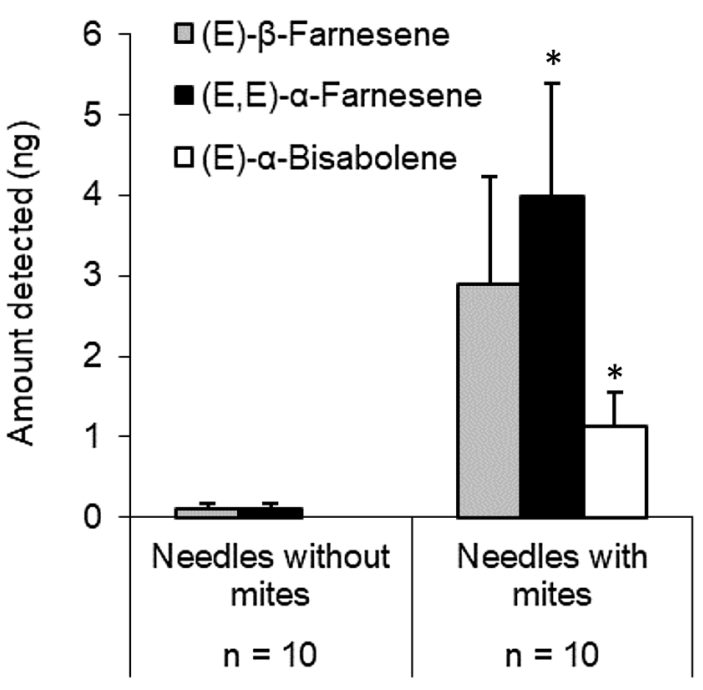

Fig. 3 The amount of $(E)$ - $\beta$-farnesene, $(E, E)$ - $\alpha$-farnesene and $(E)$ $\alpha$-bisabolene (mean $\pm S E$ ) released from Norway spruce needles, infested and uninfested by the spruce spider mite (Oligonychus ununguis). The stars denote significant differences at $\mathrm{p}=0.05$ level between the emission from uninfested needles and needles infested with spruce spider mite

\section{Selectivity of SPME: SPME competition analysis}

No significant competition in adsorption was found for terpenes when water was added to the filter paper in the glass tube (Fig. 4). No competition was found for $(E)$ - $\beta$-farnesene, neither under a high concentration of water $(p=0.87)$ nor when terpenes were mixed with a similar portion of $(E)$ $\beta$-farnesene $(p=0.48)$. Five $-10 \%$ of the $(E)$ - $\beta$-farnesene applied on the filter paper was detected by SPME-GC-MS. 


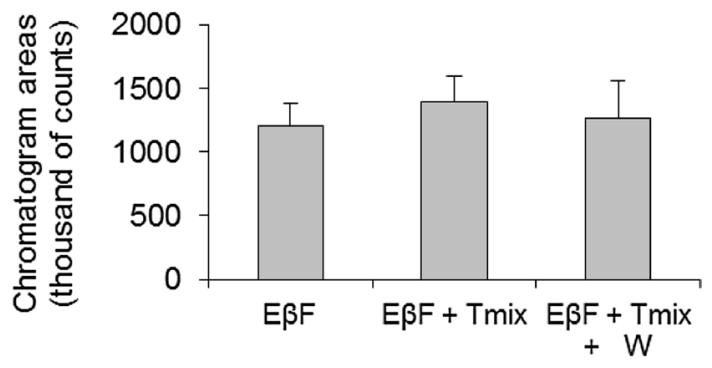

Fig. 4 SPME competition experiment using $(E)-\beta$-farnensene $(\mathrm{E} \beta \mathrm{F})$ as a representative to determine if the presence of tree terpenes $(\mathrm{E} \beta \mathrm{F}+\mathrm{Tmix})$, or terpenes with water vapour $(\mathrm{E} \beta \mathrm{F}+\mathrm{Tmix}+\mathrm{W})$ influence the quantification of stress-related volatiles released from Norway spruce. The data were presented as mean $\pm \operatorname{SE}(n=7)$. No statistical differences detected

\section{Discussion}

The unobtrusive and non-disturbing nature of using an SPME fibre inserted in a narrow glass tube makes it a suitable method for following the stress reaction of individual needles by needle feeding arthropods and, probably, local microbial infestations. This miniaturized tool allows detailed (in situ) studies of the chemical ecology of small arthropods associated with micro sites. Methyl jasmonate (MeJA), a well-known plant hormone with systemic functions, and spider mite sucking on needles causing defence reactions were used to induce plant microsite stress. Emissions released from both MeJA-treated and mite-infested single needles indicated a strict local reaction in plants This means that the emissions of spruce seedlings not only differ between individuals (Lundborg et al. 2016a, b, 2018), and different parts of the same plant (Persson et al. 1996) but, as in this study, between closely growing individual needles. We expect a similar reliability of the SPME approach for plant specific volatile studies with other plant-stressor systems.

Thus, this narrowly induced chemical response should allow arthropods to recognize and locate stressed/infested sites on spruce with high precision, being either attracted or repelled. For instance, certain egg parasitoids are attracted to eggs placed on spruce needles which cause emission of $(E)$ - $\beta$-farnesene from the needles (Hilker and Fatouros 2015 and references therein). Many Aphid species are known to produce $(E)$ - $\beta$-farnesene as their alarm pheromone. A special case is the spruce aphid Cinara pilicornis Walker (Hemiptera, Aphididae) that feed and reproduce on spruce. The feeding activity of the aphids results in local emissions of the spruce defence compound (E)- $\beta$-farnesene. It is unknown whether $C$. pilicornis also produce $(E)$ - $\beta$-farnesene as an alarm pheromone or if they use other compounds (Pettersson et al. 2008). It is possible that the emission of $(E)$ - $\beta$-farnesene has a disruptive function on spruce aphid predators making it advantageous for the aphids to exist in such an odour plume.

The medium polar fibres used in the SPME have been shown to be appropriate for the isolation of sesquiterpenes (Fäldt et al. 2000). However, this porous fibre type works through the process of adsorption, and competition may occur on the fibre (Gorecki et al. 1999). At a low concentration, such as the amounts emitted from one needle, not all sites of the fibre will be occupied by volatile sesquiterpenes, and competition between stress-induced plant volatiles will occur at higher concentrations. To investigate if the terpenes and water vapour released by the plants might influence the quantification of stress-related compounds, an SPME competition experiment, i.e. comparison for certain volatile compounds, was performed using compounds at a similar concentration as the $(E)$ - $\beta$-farnesene detected from the headspace of single needles. Similarly, we did not detect any SPME competition between terpene mixture and $(E)-\beta$-farnesene and the water vapour in the headspace (mimicking evaporation by the needle) did not appear to influence the quantification of (E,E)- $\alpha$-farnesene (Fig. 4).

$(E)$ - $\beta$-Farnesene, $(E, E)$ - $\alpha$-farnesene, $(E)$ - $\alpha$-bisabolene and (-)-linalool are the main compounds released by spruce in response to different stressors and are released already after $6 \mathrm{~h}$ after stress exposure (Kännaste et al. 2009; Martin et al. 2003; Miller et al. 2005; Mumm et al. 2003). This makes them suitable target compounds for stress monitoring of e.g. conifer forests. Martin et al. (2003) found that the rate of linalool emission increased more than 100-fold and sesquiterpenes increased more than 30-fold after treatment of whole spruce seedlings with MeJA. Recently, a broad study on maritime pine (Pinus pinaster) defence strategy (López-Goldar et al. 2018) showed that MeJA treatment on seedlings with high genetic variation induced most of the constituents in stem resin except flavonoids. Here, we used open-crossing of Norway spruce seedlings for MeJA treatments and clonal trees for the mite experiment. Although open-crossing seedlings would have a larger variation in stress response than clonal material due to a higher genetic variation, the results showed that both mite infestations and MeJA treatment induced the emission of these stress-related volatiles.

Our results may also be applicable to atmospheric chemistry research where a major challenge is to identify and judge the importance of sources, structures and oxidation products of organic aerosols emitted from living organisms (Goldstein and Galbally 2007). In a recent study of aerosols from boreal forests, sesquiterpenes like $(E)-\beta$ farnesene and $\beta$-caryophyllene contributed substantially to forest emissions during the summer (Faiola et al. 2018; Hellén et al. 2018). With a warming climate, it might be of interest to calculate terpene emission rates of infested 
needles, which are collectively high and thus contribute to the total emission of a stressed spruce forest.

Acknowledgements We are grateful to Formas-The Swedish Research Council for Environment, Agricultural Sciences and Spatial Planning for financial support, to anonymous reviewers for improving the manuscript and to Dr. Douglas Jones, SLU, Swedish University of Agricultural Sciences (Drottningholm), for linguistic revision.

Open Access This article is distributed under the terms of the Creative Commons Attribution 4.0 International License (http://creativeco mmons.org/licenses/by/4.0/), which permits unrestricted use, distribution, and reproduction in any medium, provided you give appropriate credit to the original author(s) and the source, provide a link to the Creative Commons license, and indicate if changes were made.

\section{References}

Aartsma Y, Bianchi FA, Werf WVD, Poelman EH, Dicke M (2017) Herbivore-induced plant volatiles and tritrophic interactions across spatial scales. New Phytol 216:1054-1063. https://doi. org/10.1111/nph.14475

Araniti F, Pantò S, Lupini A, Sunseri F, Abenavoli MR (2018) Chemical characterization of volatile organic compounds (VOCs) through headspace solid phase micro extraction (SPME). In: Sánchez-Moreiras AM, Reigosa MJ (eds) Advances in plant ecophysiology techniques. Springer International Publishing AG, USA, pp 401-417

Augusto F, Valente ALP (2002) Applications of solid-phase microextraction to chemical analysis of live biological samples. Trends Anal Chem 21:428-438. https://doi.org/10.1016/S0165 -9936(02)00602-7

Björklund N, Nordlander G, Bylund H (2005) Olfactory and visual stimuli used in orientation to conifer seedlings by the pine weevil, Hylobius abietis. Physiol Entomol 30:225-231

Borg-Karlson A-K, Mozuraitis R (1996) Solid phase micro extraction technique used for collecting semiochemicals. Identification of volatiles released by individual signalling phyllonorycter sylvella moths. Z Naturfrosch 51c:599-602

Chung JH, Song GC, Ryu CM (2016) Sweet scents from good bacteria: case studies on bacterial volatile compounds for plant growth and immunity. Plant Mol Biol 90:677-687

Copolovici L and Niinemets Ü (2016) Environmental impacts on plant volatile emission. In Blande JD, Glinwood R (eds), Deciphering chemical language of plant communication, signaling and communication in plants. Springer International Publishing, Switzerland, pp 35-59

D'Alessandro M, Turlings TCJ (2006) Advances and challenges in the identification of volatiles that mediate interactions among plants and arthropods. Analyst 131:24-32. https://doi.org/10.1039/b5075 $89 \mathrm{k}$

Dudareva N, Negre F, Nagegowda DA, Orlova I (2006) Plant volatiles: recent advances and future perspectives. Crit Rev Plant Sci 25:417-440. https://doi.org/10.1080/07352680600899973

Faiola CL, Buchholz A, Kari A, Yli-Pirilä P, Holopainen JK, Kivimäenpää M, Miettinen P, Worsnop DR, Lehtinen KEJ, Guenther AB, Virtanen A (2018) Terpene composition complexity controls secondary organic aerosol yields from scots pine volatile emissions. Sci Rep 8:3053

Fäldt J, Eriksson M, Valterova I, Borg-Karlson AK (2000) Comparison of headspace techniques for sampling volatile natural products in a dynamic system. Z Naturforsch 55c:180-188
Franceschi VR, Krekling T, Christiansen E (2002) Application of methyl jasmonate on picea abies (pinaceae) stems induces defense-related responses in phloem and xylem. Am J Bot 89:578-586. https://doi.org/10.3732/ajb.89.4.578

Franceschi VR, Krokene P, Christiansen E, Krekling T (2005) Anatomical and chemical defenses of conifer bark against bark beetles and other pests. New Phytol 167:353-375. https://doi.org/10.111 1/j.1469-8137.2005.01436.x

Goldstein AH, Galbally IE (2007) Known and unexplored organic constituents in the earth's atmosphere. Environ Sci Technol 41:1514-1521. https://doi.org/10.1021/es072476p

Gorecki T, Yu X, Pawliszyn J (1999) Theory of analyte extraction by selected porous polymer spme fibres. Analyst 124:643-649. https://doi.org/10.1039/a808487d

Hellén H, Praplan AP, Tykkä T, Ylivinkka I, Vakkari V, Bäck J, Petäjä T, Kulmala M, Hakola H (2018) Long-term measurements of volatile organic compounds highlight the importance of sesquiterpenes for the atmospheric chemistry of a boreal forest. Atmos Chem Phys 18:13839-13863. https://doi. org/10.5194/acp-18-13839-2018

Hilker M, Fatouros NE (2015) Plant responses to insect egg deposition. Annu Rev Entomol 60:493-515

Kännaste A, Nordenhem H, Nordlander G, Borg-Karlson A-K (2009) Volatiles from a mite-infested spruce clone and their effects on pine weevil behavior. J Chem Ecol 35:1262-1271. https://doi. org/10.1007/s10886-009-9708-3

Krokene P (2015) Conifer defense and resistance to bark beetles. In: Vega FE, Hofstetter RW (eds) Bark beetles: biology and ecology of native and invasive species. Elsevier Academic Press, San Diego, pp 177-207

Kurz WA, Dymond CC, Stinson G, Rampley GJ, Neilson ET, Carroll AL, Ebata T, Safranyik L (2008) Mountain pine beetle and forest carbon feedback to climate change. Nature 452:987-990. https://doi.org/10.1038/nature06777

López-Goldar X, Villari C, Bonello PE, Borg-Karlson A-K, Grivet D, Zas R, Sampedro L (2018) Inducibility of plant secondary metabolites predicts genetic variation in resistance against a key insect herbivore in maritime pine. Front Plant Sci https://doi. org/10.3389/fpls.2018.01651

Lundborg L, Fedderwitz F, Björklund N, Nordlander G, Borg-Karlson A-K (2016a) Induced defenses change the chemical composition of pine seedlings and influence meal properties of the pine weevil Hylobius abietis. Phytochemistry 130:99-105. https ://doi.org/10.1016/j.phytochem.2016.06.002

Lundborg L, Nordlander G, Björklund N, Nordenhem H, Borg-Karlson A-K (2016b) Methyl jasmonate-induced volatiles in Scots pine and Norway spruce tissues affect pine weevil orientation. J Chem Ecol. https://doi.org/10.1007/s10886-016-0790-zopen access

Lundborg L, Sampedro L, Zas R, Borg-Karlson A-K (2018) Effects of methyl jasmonate on the concentration of volatile terpenes in tissues of Maritime pine and Monterey pine and its relation to pine weevil feeding. https://doi.org/10.1007/s00468-018-1757-1

Mani V (1999) Properties of commercial spme coatings. In: Pawliszyn J (ed) Applications of solid phase microextraction, Royal Society of Chemistry, Cambridge,pp 57-72

Martin DM, Gershenzon J, Bohlmann J (2003) Induction of volatile terpene biosynthesis and diurnal emission by methyl jasmonate in foliage of Norway spruce. Plant Physiol 132:1586-1599. https://doi.org/10.1104/pp.103.021196

Miller JN, Miller JC (2005) Statistics and chemometrics for analytical chemistry, 5th edn. Pearson Prentice Hall, Harlow

Miller B, Madilao LL, Ralph S, Bohlmann J (2005) Insect-induced conifer defense. White pine weevil and methyl jasmonate induce traumatic resinosis, de novo formed volatile emissions, and accumulation of terpenoid synthase and putative octadecanoid 
pathway transcripts in sitka spruce. Plant Physiol 137:369-382. https://doi.org/10.1104/pp.104.050187

Mumm R, Schrank K, Wegener R, Schulz S, Hilker M (2003) Chemical analysis of volatiles emitted by Pinus sylvestris after induction by insect oviposition. J Chem Ecol 29:1235-1252. https:// doi.org/10.1023/A:1023841909199

Persson M, Sjödin K, Borg-Karlson A-K, Norin T, Ekberg I (1996) Relative amounts and enantiomeric compositions of monoterpene hydrocarbons in xylem and needles of picea abies. Phytochemistry 42:1289-1297. https://doi.org/10.1016/00319422(96)00119-7 ।

Petterson M, Valterová I, Unelius CR, Borg-Karlson A-K (2008) Semiochemicals related to the aphid Cinara pilicornis (Hartig) and its host. Picea abies. A method to assign nepetalactone diastereomers. J Chromatogr A 1180:165-170
Phillips MA, Bohlmann J, Gershenzon J (2006) Molecular regulation of induced terpenoid biosynthesis in conifers. Phytochem Rev 5:179-189. https://doi.org/10.1007/s11101-006-0001-6

Zhang Z, Pawliszyn J (1993) Headspace solid-phase microextraction. Anal Chem 65:1843-1852. https://doi.org/10.1021/ac00062a008

Zhao T, Krokene P, Hu J, Christiansen E, Björklund N, Långström B, Solheim H, Borg-Karlson A-K (2011) Induced terpene accumulation in Norway spruce inhibits bark beetle colonization in a dose-dependent manner. PLoS ONE 6:e26649

Publisher's Note Springer Nature remains neutral with regard to jurisdictional claims in published maps and institutional affiliations. 